\title{
Prevalence of Anemia and Associated Factors Among Pregnant Women Attending Antenatal Care Service in Worabe Comprehensive Specialized Hospital, Silte Zone, SNNPR State, Ethiopia
}

Neja Awol Mohammed ( $\square$ nejaawol2@gmail.com )

Worabe Comprehensive Specialized Hospital

Research note

Keywords: Anaemia, Prevalence, Antenatal Care, Ethiopia

Posted Date: August 3rd, 2021

DOl: https://doi.org/10.21203/rs.3.rs-770183/v1

License: (9) This work is licensed under a Creative Commons Attribution 4.0 International License.

Read Full License 


\section{Abstract}

Objective

The aim of this study was to determine the prevalence ofanaemia and associated factor among pregnant women attending ANC service in Worabe Comprehensive Specialized Hospital from September to December 2016, Silte ZoneSouthern Ethiopia.

Method

A Cross-sectional study was conducted from September to December 2016.on pregnant women. Demographic and other required data that has association contributing for the occurrence of anaemia in pregnant women was collected using pre structured questionnaires, \& haemoglobin were measured using Mindray CD-3200 Machine. The association of data collected with independent variable are analysed by using SPSS and possible conclusions and recommendations was forwarded depending on the findings.

\section{Introduction}

Anaemia is defined as a condition in which there is less than the normal haemoglobin ( $\mathrm{Hgb})$ level in the body, which decreases oxygen-carrying capacity of red blood cells to tissues(1).

Anemia affects the lives of more than 2 billion people globally, accounting for over $30 \%$ of the world's population. Anemia is a global public health problem occurring at all stages of the life cycle but the burden of the problem is higher in pregnant women particularly in developing countries (2). The prevalence of anemia in developing and developed countries is estimated to be $43 \%$ and $9 \%$, respectively(3).

Sub-Saharan Africa is the most affected region, with anemia prevalence among pregnant women estimated to be 17.2 million, which corresponds to approximately $30 \%$ of total global cases(4).

In Ethiopia nearly $17 \%$ of women with age $15-49$ are anemic of these $22 \%$ are pregnant women(5).

World Health Organization (WHO)definitions for anaemia differ by age, sex and pregnancy status as follows: children 6 months to 5 year anaemia is defined as a $\mathrm{Hgb}$ level $<11 \mathrm{~g} / \mathrm{dl}$, children $5-11$ years $\mathrm{Hgb}$ $<11.5 \mathrm{~g} / \mathrm{dl}$, adult males $\mathrm{Hgb}<13 \mathrm{~g} / \mathrm{dl}$; non pregnant women $\mathrm{Hgb}<12 \mathrm{~g} / \mathrm{dl}$ and pregnant women $\mathrm{Hgb}<$ $11 \mathrm{~g} / \mathrm{dl}[6]$.The World Health Organization (WHO) defined anaemia as haemoglobin concentration below $11 \mathrm{~g} / \mathrm{dl}$ in pregnancy. Anaemia in pregnancy is associated with increased rates of maternal and perinatal mortality, premature delivery, low birth weight and other adverse outcomes. The probable predisposing factors for anaemia in pregnant women include parity, low socioeconomic status and substance abuse among others [7].

Anaemia in pregnant women is often caused by iron deficiency, which is the most common nutrient deficiency in the world. It has been estimated that, in developing countries, half of the population (mainly 
children and women of reproductive age) is affected by anaemia[8]. Anaemia also could be caused due to increased haemolysis, diminished erythropoiesis and blood loss. Among the other causes of anaemia,heavy blood loss because of menstruation or parasitic infections can lower blood haemoglobin $(\mathrm{Hgb})$ concentration. Acute and chronic infections, including malaria can also lower blood $\mathrm{Hgb}$ concentration. The presence of other micronutrient deficiencies can also increases the risk of anaemia[8].

Anaemia in pregnancy remains one of the most intractable public health problems in developing countries. It is extremely common and although not always shown to have a causal link, severe anaemia contributes to maternal morbidity and mortality. Anaemia, even when mild to moderate affects the sense of well-being resulting in fatigue, stress and reduced work productivity. During labour, women with severe anaemia are less able to endure moderate blood loss and as a consequence are at a higher risk of requiring a blood transfusion during delivery, thus exposing patients unnecessarily to the risk of infection with human immunodeficiency virus (HIV) and other blood borne pathogens[8].

In Ethiopia, anaemia prevalence of $41.9 \%$ and $51.9 \%$ was reported among pregnant women attending ANC from Jimma and Bushulo health canters, respectively [9].

The availability of local prevalence statistics has a major role in the management and control of anaemia in pregnancy. However, it was not adequately done in the study area.Therefore, this study aimed to assess the prevalence and associated risk factors anaemia among pregnant women at Worabe Comprehensive Specialized Hospital.

\section{Methods}

\section{Study area}

Worabe townis the capital city of Silt zone which is found in SNNPR. Werabe town which is $185 \mathrm{~km}$ Far away from Addis Ababa with the total population of 26,839 in 2007 E.CAnd using $3.8 \%$ conversion factor for reproductive age group the source of population will be $N=894$. The weather condition is partially desert "Qola" in which its altitude is 1450 - 2200 meters above sea level and bordered with MaskanWoreda in North, HulbaragWoredainSouth,AlichoWoredainWest and DalochaWoredain East. In Werabe town Health service there are 1 hospital, 1 health centre, 2 health post, and 5 privet clinics.

\section{Source of population}

The source population all pregnant women living in Worabe town

\section{Study population}

The Study populations were all pregnant women who came from Worabe town for antenatal care service to Worabe comprehensive specialized hospital ANC clinic during the study period.

\section{Study design and study period}


A hospital-based cross-sectional study was conducted from September to December 2016 to assess the prevalence of anemia and associated factors among pregnant women in Worabe comprehensive specialized hospital, Silt Zone, Southern Ethiopia.

\section{Sample size determination}

Sample size was calculated by using a single population proportionformula.

$n=Z^{2} \times P \times(1-P) / D^{2}$

Where n: sample size

Z: reliability coefficient (confidence level) which is $95 \%=1.96$

P: estimate prevalence rate for the population $0.5(50 \%)$

D: the margin of error, which is $5 \%=0.04$

$n=1.96^{2} \times(0.5) \times(1-0.5) / 0.05^{2}=384$,

$\mathrm{n}=384$

The total population is less than 10,000 . The above formula result is manipulated using the formula as follows.

$\mathrm{Nf}=\underline{\mathrm{n}}$

$1+\underline{n} \quad$ Where $\mathrm{N}=894$

$\mathrm{N} \quad \mathrm{n}=384$

Then find sample size by using the below formula

$\underline{384}$

$1+\underline{384}$

894

$\mathrm{Nf}=\underline{\underline{268}}$

contingency for non response

$268 \times 10 \%=26.8$

Total sample is $=268+27=\mathbf{2 9 5}$ 
Therefore, the total sample size required to collect the data is nearly where $\mathbf{2 9 5}$ pregnant women.

\section{Sampling technique}

Convenient sampling technique wasused to select the $\mathbf{2 9 5}$ pregnant women who come to Worabe comprehensive specialized hospital during study period was studied.

\section{Data collection procedure}

Before data collection, Pre structured questionnaires is prepared in English, and translated to Amharic by language experts and then back to English. Then the required information is collected by face-to-face interview using pre-tested structured questionnaire until adequate sample is found.

\section{Data management and quality control}

To ensure the quality of the data, the following action was taken. Orientation was given to health professional about study and how to collect data from ANC service attendants. And also the issue was discussed with laboratory staffs to give due emphasis to study. The questionnaire was pre-tested on $5 \%$ of the sample at Worabe health center who are not included in the study..

\section{Data processing and analysis}

Data were entered, cleaned, coded and analyzed using statistical package for social science (SPSS) version 16. Data were organized, summarized, and presented in descriptive statistical methods. A p-value of $\leq 0.05$ was considered as statistically significant association between the the dependant and independent variables by using chi-square/Fishers test and presented using tables and graphs.

\section{Results}

\section{Sociodemographic characteristics}

From 295 pregnant Women who visit Worabe comprehensive specialized hospital for their antenatal care were involved in the study during the study period of Sep to Dec 2016. The age range of the studied pregnant women was 15-40years old. Of this age group the majority was 20-25 years old which account $129(43.7 \%)$. The least age group was above 34 years old, which accounts $13(4.4 \%)$.

Among the total 295 pregnant women 125 (42.4\%) are Illiterate and 26(8.8\%) were above 12 grade \&the rest $3(1.01 \%)$ were can read and write. 
Table 1

Socio demographic factor among pregnant women attending ANC in worabe comprehensive specialized hospital,Southern Ethiopia, September to December $2016(n=295)$.

\begin{tabular}{|c|c|c|c|c|c|c|}
\hline Characteristic & & $\begin{array}{l}\text { Anaemic } \\
(\%)\end{array}$ & $\begin{array}{l}\text { Non } \\
\text { anaemic } \\
\text { (\%) }\end{array}$ & $\begin{array}{l}\text { Total } \\
295\end{array}$ & $\begin{array}{l}\text { Chi } \\
\text { square } \\
\text { test } \\
\text { value }\end{array}$ & $\begin{array}{l}\mathrm{P} \text { - } \\
\text { value }\end{array}$ \\
\hline \multirow[t]{5}{*}{ Age groups } & $15-19$ & $16(32 \%)$ & $35(68 \%)$ & $51(100 \%)$ & \multirow[t]{5}{*}{1.110} & \multirow[t]{5}{*}{0.893} \\
\hline & $20-24$ & $49(32 \%)$ & $80(68 \%)$ & $129(100 \%)$ & & \\
\hline & $25-29$ & $26(37.1 \%)$ & $44(62.9 \%)$ & $70(100 \%)$ & & \\
\hline & $30-34$ & 11(39.3\%) & $17(60.7 \%)$ & $28(100 \%)$ & & \\
\hline & $>34$ & $5(46.2 \%)$ & $12(53.8 \%)$ & $17(100 \%)$ & & \\
\hline \multirow[t]{2}{*}{ Resident } & Urban & $52(28.7 \%)$ & $130(71.3 \%)$ & $182(100 \%)$ & \multirow[t]{2}{*}{11.526} & \multirow[t]{2}{*}{0.001} \\
\hline & Rural & $55(48.2 \%)$ & $58(51.8 \%)$ & $113(100 \%)$ & & \\
\hline \multirow{7}{*}{$\begin{array}{l}\text { Respondent } \\
\text { educational status }\end{array}$} & Illiterate & $54(43.2 \%)$ & $71(56.8 \%)$ & $125(100 \%)$ & \multirow[t]{7}{*}{11.362} & \multirow[t]{7}{*}{0.088} \\
\hline & $\begin{array}{l}\text { Can read and } \\
\text { write }\end{array}$ & $1(33.3 \%)$ & $2(66.7 \%)$ & $3(100 \%)$ & & \\
\hline & $1-4$ & $5(41.7 \%)$ & $7(58.3 \%)$ & $12(100 \%)$ & & \\
\hline & $5-8$ & $13(23.6 \%)$ & $42(76.4 \%)$ & $55(100 \%)$ & & \\
\hline & $9-10$ & $24(42.1 \%)$ & $33(57.9 \%)$ & $57(100 \%)$ & & \\
\hline & $11-12$ & $4(23.5 \%)$ & $13(76.5 \%)$ & $17(100 \%)$ & & \\
\hline & $>12$ & $6(23.1 \%)$ & $20(76.9 \%)$ & $26(100 \%)$ & & \\
\hline \multirow{6}{*}{$\begin{array}{l}\text { Respondent } \\
\text { Occupation }\end{array}$} & House wife & $83(37.2 \%)$ & $140(62.8 \%)$ & $223(100 \%)$ & \multirow[t]{6}{*}{8.080} & \multirow[t]{6}{*}{0.382} \\
\hline & Merchant & $9(52.9 \%)$ & $8(47.1 \%)$ & $17(100 \%)$ & & \\
\hline & Farmer & $0(0 \%)$ & $1(100 \%)$ & $1(100 \%)$ & & \\
\hline & Daily lab our & $0(0 \%)$ & $1(100 \%)$ & $1(100 \%)$ & & \\
\hline & $\begin{array}{l}\text { Government } \\
\text { employer }\end{array}$ & $13(27.1 \%)$ & $35(72.9 \%)$ & $48(100 \%)$ & & \\
\hline & Other-student & $2(40 \%)$ & $3(60 \%)$ & $5(100 \%)$ & & \\
\hline
\end{tabular}

\section{Prevalence of Anaemia}

Out of 295 pregnant women who were examined for intestinal parasite all pregnant mother are negative for ova of parasite and they were also negative for malaria parasite.

Factors associated with the prevalence of Anaemia 
Table 2

Socio economic factor among pregnant women attending ANCin worabe comprehensive specialized hospital,Southern Ethiopia, September to December $2016(n=295)$.

\begin{tabular}{|c|c|c|c|c|c|c|}
\hline Characteristic & & $\begin{array}{l}\text { Anaemic } \\
(\%)\end{array}$ & $\begin{array}{l}\text { Non } \\
\text { anaemic } \\
\text { (\%) }\end{array}$ & $\begin{array}{l}\text { Total } \\
295\end{array}$ & $\begin{array}{l}\text { Chi } \\
\text { square } \\
\text { test value }\end{array}$ & $\begin{array}{l}\mathrm{P} \text { - } \\
\text { value }\end{array}$ \\
\hline \multirow[t]{4}{*}{ Food feed } & One/perday & $8(61.5 \%)$ & $5(38.5 \%)$ & $13(100 \%)$ & \multirow[t]{4}{*}{13.751} & \multirow[t]{4}{*}{0.002} \\
\hline & Two/perday & $51(45.9 \%)$ & $60(54.1 \%)$ & $111(100 \%)$ & & \\
\hline & Three/perday & $48(28.4 \%)$ & 121(71.6\%) & $169(100 \%)$ & & \\
\hline & Other & $0(0 \%)$ & $2(100 \%)$ & $2(100 \%)$ & & \\
\hline \multirow[t]{4}{*}{ Meal afford } & One & $39(33.1 \%)$ & $79(66.9 \%)$ & $118(100 \%)$ & \multirow[t]{4}{*}{4.064} & \multirow[t]{4}{*}{0.694} \\
\hline & Two & $33(38.4 \%)$ & $53(61.6 \%)$ & $86(100 \%)$ & & \\
\hline & Three & $24(41.4 \%)$ & $34(58.6 \%)$ & $58(100 \%)$ & & \\
\hline & Other & 11(33.3\%) & $22(66.7 \%)$ & $33(100 \%)$ & & \\
\hline \multirow{3}{*}{$\begin{array}{l}\text { Vegetable } \\
\text { consumption }\end{array}$} & Once per day & $39(23.1 \%)$ & $130(76.9 \%)$ & $169(100 \%)$ & \multirow[t]{3}{*}{35.119} & \multirow[t]{3}{*}{0.001} \\
\hline & $\begin{array}{l}\text { Less than once } \\
\text { per day }\end{array}$ & $59(51.8 \%)$ & $55(48.2 \%)$ & $114(100 \%)$ & & \\
\hline & Other & $9(5 \%)$ & $3(25 \%)$ & $12(100 \%)$ & & \\
\hline \multirow{5}{*}{$\begin{array}{l}\text { Meat } \\
\text { Consumption }\end{array}$} & 1 & $54(35.1 \%)$ & $100(64.9 \%)$ & $154(100 \%)$ & \multirow[t]{5}{*}{6.772} & \multirow[t]{5}{*}{0.282} \\
\hline & $<1$ & $16(53.3 \%)$ & $14(46.7 \%)$ & $30(100 \%)$ & & \\
\hline & $2-4$ & $33(32.7 \%)$ & 68(67.3\%) & $101(100 \%)$ & & \\
\hline & $>5$ & $3(37.5 \%)$ & $5(62.5 \%)$ & $8(100 \%)$ & & \\
\hline & Other & $1(50 \%)$ & $1(50 \%)$ & $2(100 \%)$ & & \\
\hline \multirow{5}{*}{$\begin{array}{l}\text { Egg } \\
\text { Consumption }\end{array}$} & 1 & 71(37.4\%) & $119(62.6 \%)$ & $190(100 \%)$ & \multirow[t]{5}{*}{9.333} & \multirow[t]{5}{*}{0.055} \\
\hline & $<1$ & $22(50 \%)$ & $22(50 \%)$ & $44(100 \%)$ & & \\
\hline & $2-4$ & $12(23.1 \%)$ & $40(76.9 \%)$ & $52(100 \%)$ & & \\
\hline & $>5$ & $1(16.7 \%)$ & $5(83.3 \%)$ & $6(100 \%)$ & & \\
\hline & Other & $1(33 \%)$ & $2(66 \%)$ & $3(100 \%)$ & & \\
\hline
\end{tabular}

Among 295 pregnant mother who feed three times per day 48(28.4\%) of them were anaemic and the rest $121(71.6 \%)$ of them were non anaemic. Pregnant mother who drink milk one time per day $39(33.1 \%)$ are anaemic, $79(66.9 \%)$ where non anaemic. In terms of vegetable consumption pregnant women who eat less than once per day 59(51.8\%) of them were anaemic 55(48.2\%) whereas non anaemic. 


\section{Discussion}

Anemia is a major health problem \& it remains a major contributing factor for high maternal \& prenatal morbidity \& mortality in the developing countries. The prevalence of anemia among pregnant women in this study was $36.3 \%$. The overall prevalence of anemia among pregnant women attending ANC in the current study was found to be $36.3 \%$ which is lower than a study conducted in India (87-100\%), Boditi (61.6\%), and Godetown, Eastern Ethiopia (56.8\%) [10-13].Similarly the prevalence of this study was lower than studies conducted in Gelgilgbedam West Ethiopia (53.9\%) [4]. Similar study reported from South West Ethiopia shown higher prevalence than this study, which was $57 \%$ had been reported in pregnant women in Jimma[14]this might be due to different in geographical area, study population and study period.

The prevalence of anemia among pregnant women in this study was $36.3 \%$ this finding inlines with studies conducted in Tigray region North West zone Northern Ethiopia and Jimma town South West Ethiopia [15]. According to our finding36.3\% was higher than studies conducted in Azezo health center, Gonder town North West Ethiopia and Tikuranbesa hospital Addis Ababa Ethiopia [6].

The prevalence of anemia in Rural respondents was 55(48.2\%) which was higher than the prevalence of anemia of urban respondents $52(28.7 \%)$ which is Similar with the study conducted atsouth eastern Ethiopia(16)this might be due to less educational status \& less economy level.

The prevalence of anemia was significantly associated with parity. And high prevalence of anemia was seen in multigravida pregnant studied women which were $70(39.1 \%)$ this was might be due to repeated blood loss during the previous pregnancy. Higher prevalence of anemia was seen in second trimester of the studied pregnant women which accounts $49(39.2 \%)$,this may be due to the relative increase in plasma volume.

The prevalence of anemia was higher $54(43.5 \%)$ among pregnant women who are not educated(illiterate) as compared to those pregnant women who are educated in which pregnant women who were not educated were risk to be anemic as compared to pregnant women who had formal education. The reason for this might be the fact that pregnant women who have some level of formal education can be aware of anemia during pregnancy and take some preventive measures like eating iron-rich food and taking iron or lack of awareness. The result of this study is consistent with other studies conducted in AddisAbaba[7], West Bengal [17], and West Algeria[18].

The prevalence of anemia was higher among pregnant women having a meal frequency of one times per day as compared to pregnant women who had a meal frequency of two times per day in which the pregnant women having a meal frequency of onetimes per day 39(33.1\%)were at two times 33(38.4\%) higher risk of developing anemia which is consistent with other studies conducted in Mekele[3] and West Arsi[19].This might be due to the reason that pregnancy is a critical period with increased energy and nutrient demand for the mother which should be fulfilled with increased meal frequency per day. 


\section{Conclusion}

High prevalence of anaemia was observed in pregnant women who were illiterate. Statistical significance between anaemia \& occupation and gravid was seen Anaemia had statistical association with multi gravid pregnant women.

We recommend all pregnant women should be encouraged by health extension workers \& by other health related professionals to ANC.Health education must be given for pregnant women about pre-disposing factors for anaemia\& the consequence of anaemia during ANC.

\section{Abbreviations}

ANC - Antenatal Care, Hgb - Haemoglobin, Hct - Hematocrite, PCV - Packed cell volume, RBCs - Red blood cells, $\mathrm{MCH}$ - Maternal and child health, CBC-Complet blood count, WHO -World health organization, HU-HaramayaUnversity, QC-Quality Control, IDA-Iron deficiency anemia, EDHS-Ethiopia demographic health survey

\section{Declarations}

\section{Ethical approval and consent to participate}

Prior to data collection letter of approval was obtained from Institutional Review Board (IRB) of Haramaya UniversityAR/A/D/1319/07. Permission was also obtained from the concerned bodies of Worabe Comprehensive Specialized Hospital. Written informed consent was obtained from each study participant.

\section{Consent for publication}

Not applicable

\section{Availability of data and material}

The datasets used and analyzed during the current study available from the corresponding author on reasonable request.

\section{Competing Interests}

No competing interests exist

\section{Funding}

The reagent needed for the study was supported from Worabe Comprehensive Specialized Hospital

\section{Authors' contributions}


${ }^{\mathrm{BD}}$ Conceived designed the experiments, laboratory work, and data analysis and write up ${ }^{\mathrm{NA}}$ review, supervision, analysis and manuscript preparationreview, ${ }^{\mathrm{BF}}$ supervision, data analysis and write up ${ }^{\mathrm{YA}}$ review, supervision, analysis and manuscript preparation.All authors have read and approved the final manuscript.

\section{Acknowledgment}

Worabe Comprehensive Specialized Hospital is greatly acknowledged for the accomplishment of this research. We greatly appreciate Worabe Comprehensive Specialized Hospital Laboratory for cooperation during the study.

\section{References}

1. FilagotKefiyalew, EndalewZemene, YaregalAsres and LealemGedefaw. Anemia among pregnant women in Southeast Ethiopia: prevalence, severity and associated risk factors. BMCResearch Notes 2014 7:771.http://www.biomedcentral.com/1756-0500/7/771

2. Jufar AH, Zewde T. Prevalence of anemia among pregnant women attending antenatal care at TikurAnbessa specialized hospital, Addis Ababa Ethiopia. J Hematol Thromboembolic Dis. 2014;2(1):2-6.

3. A. Abriha, M. E. Yesuf, and M. M. Wassie, "Prevalence and associated factors of anemia among pregnant women of Mekelle town: a cross sectional study," BMC Research Notes, vol. 7, article 888, 2014.

4. A. Bilimale, J. Anjum, H. N. Sangolli, and M. Mallapur, "Improving adherence to oral iron supplementation during pregnancy," Australasian Medical Journal, vol. 3, no. 5, pp. 281-290, 2010.

5. CSA [Ethiopia] and ORC Macro: Ethiopian Demographic and Health Survey.Addis Ababa, Ethiopia;2011.

6. MeseretAlem BE, Aschalew G, Tigist K, Mohammed S, Olkeba Y: Prevalence of anemia and associated risk factors among pregnant women attending antenatal care in Azezo Health Center Gondar town, Northwest Ethiopia. J InterdiscipHistopathol 2013, 1(3):(2146-8362):137-144.

7. FatemehMirzaie M.D., NahidEftekhari M.D., SedighehGoldozeian M.D., JamilehMahdavinia M.D. Prevalence of anemia risk factors in pregnant women in Kerman, Iran. Journal of Reproductive Medicine 2010, 8(2): 66-69.

8. F.I. Buseri, E. K. Uko, Z. A. Jeremiah, and E.A. Usanga. Prevalence and Risk Factors of Anaemia among Pregnant women in Nigeria. The Open Haematology Journal, 2008, 2:14-19

9. Getachew M, Yewhalaw D, Tafess K, Getachew Y, Zeynudin A. Anaemia and associated risk factors among pregnant women in Gilgel Gibe dam area, southwest Ethiopia. Parasites Vectors. 2012; 5 (1):296.

10. M.Melku, Z.Addis, M. Alem, and B. Enawgaw, "Prevalence and predictors of maternal anemia during pregnancy in Gondar, Northwest Ethiopia: an institutional based cross-sectional study," Anemia, vol. 
2014,Article ID 108593, 9 pages, 2014.

11. P. O. Lokare,V.D. Karanjekar, P. L. Gattani, andA. P. Kulkarni, "A study of prevalence of anemiaandsociodemographic factors associated with anemia among pregnant women in Aurangabad city, India," Annals of NigerianMedicine, vol. 6, no. 1, pp. 30-34, 2012.

12. B. Vemulapalli and K. K. Rao, "Prevalence of anemiaamong pregnant women of rural community in Vizianagram, North coastal Andhra Pradesh, India," Asian Journal of Medical Science, vol. 5, no. 2, pp. 21-25, 2014.

13. K. A. Alene and A.M. Dohe, "Prevalence of anemia and associated factors among pregnant women in an urban area of Eastern Ethiopia," Anemia, vol. 2014,Article ID 561567, 7 pages, 2014.

14. Desalegn S: Prevalence of anemia in pregnancy in jimma town, south western Ethiopia. Ethiop Med J 1993, 31:251-258.

15. Abel Gebre and AfeworkMulugeta. Prevalence of Anemia and Associated Factors among Pregnant Women in North Western Zone of Tigray, Northern Ethiopia: A Cross-Sectional Study Journal of Nutrition and Metabolism Volume 2015, Article ID 165430, 7 http://dx.doi.org/10.1155/2015/165430

16. F. Kefiyalew, E. Zemene, Y. Asres, and L. Gedefaw, "Anemia among pregnant women in Southeast Ethiopia: prevalence, severity and associated risk factors," BMC Research Notes, vol. 7, no. 1, article 771, 2014.

17. S. Bisoi, D. Haldar, T. K. Majumdar, N. Bhattacharya, G. N.Sarkar, and S. K. Ray, “Correlates of anemia among pregnant women in a rural area of West Bengal," The Journal of Family Welfare, vol. 57, no. 1, 2011.

18. Demmouches.khelil,ands.Moulessehoul.Anemia Among Pregnant Women in the SidiBel Abbes Region (West Alegria) : An Epidemiologic Study. Journal of Blood Disorders \& Transfusion. 2011: 02(03) DOI:10.4172/2155-9864.1000113

19. Niguse O, Mossie A, Gobena T: Magnitude of anemia and associated risk factors among pregnant women attending antenatal care in shallaworeda, west arsi zone, oromia region, Ethiopia. Ethiop $J$ Health Sci 2013, 23:165-173. 